\title{
Treatment and functional result of desmoplastic fibroma with repeated recurrences in the forearm: A case report
}

\author{
JING RUI $^{1,2}$, WENJIE GUAN ${ }^{1}$, YUDONG GU $^{1,2}$ and JIE LAO ${ }^{1,3}$ \\ ${ }^{1}$ Department of Hand Surgery, Huashan Hospital, Fudan University; ${ }^{2}$ Key Laboratory of Hand Reconstruction, \\ Ministry of Health; ${ }^{3}$ Shanghai Key Laboratory of Peripheral Nerve and Microsurgery, Shanghai 200040, P.R. China
}

Received November 29, 2014; Accepted December 4, 2015

DOI: 10.3892/ol.2015.4058

\begin{abstract}
Desmoplastic fibroma, alternatively known as aggressive fibromatosis or desmoid tumors, occurs in the form of benign locally aggressive tumors that possess a high rate of recurrence. The forearm bones are rarely involved. The current study presents a case of desmoplastic fibroma in the distal forearm of a 23-year-old man. The tumor was widely resected, and the bone defect was reconstructed using an autologous vascularized fibular graft during the resection procedure. The patient experienced recurrence three times and underwent four resections during the subsequent 3 years following the initial resection. After 10 years of follow-up, the patient's functional recovery remains positive. Despite the implication that surgical resection may be involved in the development of aggressive fibromatosis, surgical wide local excision and functional reconstruction were recommended for the treatment of the present patient.
\end{abstract}

\section{Introduction}

Desmoplastic fibroma, alternatively known as aggressive fibromatosis or desmoid tumors, was initially described by MacFarlane in 1832. The annual incidence of desmoplastic fibroma is 2-4 per 1 million individuals, worldwide (1). Clinically, it presents as a monoclonal fibroblastic proliferation arising in musculoaponeurotic structures $(2,3)$. Magnetic resonance imaging (MRI) is typically used to determine the extent of the tumor and histological analysis is the gold standard for diagnosis. Desmoplastic fibroma can be treated with surgery, radiotherapy or pharmacological agents (1-3). The disease occurs in the form of benign locally aggressive tumors that possess a high rate of recurrence. Desmoplastic fibroma of the bone is rare, and the most common site of

Correspondence to: Professor Jie Lao, Department of Hand Surgery, Huashan Hospital, Fudan University, 12 Wulumuqizhong Road, Shanghai 200040, P.R. China

E-mail: laojie633@sina.com

Key words: autologous fibular graft, desmoplastic fibroma, reconstruction surgery, repeated recurrences occurrence is the jaw, followed by the pelvis and long bones. The forearm bones are rarely involved, however, the development of desmoplastic fibroma following a bone fracture has been previously reported. The majority of studies recommend surgical treatment with a wide free margin resection, followed by reconstruction of the bony defect with a fibular graft (4-7).

The current study presents a case of desmoplastic fibroma in the distal forearm treated by wide resection and reconstructive surgery during the resection procedure. The patient experienced recurrence three times and underwent four resections during the subsequent 3 years following the initial resection. After 10 years of follow-up, the patient's functional recovery remains positive. The present case indicated that repeated recurrences of limb desmoplastic fibroma are not an absolute contraindication for restoration of function, however, frequent follow-up is necessary. Written informed consent was obtained from the patient.

\section{Case report}

In October 1999, a 23-year-old man presented at Huashan Hospital, Fudan University (Shanghai, China) with a 2-year history of a progressively swelling tumor in the right forearm following spraining of the right wrist when playing basketball. The patient attended a local hospital (Cixi City, China) for conservative treatment after spraining in 1997. Upon presentation to our hospital, local examination revealed an $8 \times 5-\mathrm{cm}$ solid mass over the palmar and ulnar aspects of the wrist, with an unclear boundary and superficial varicose veins. The overlying skin was higher than normal. The patient demonstrated a full range of motion of the wrist and hand joints. Plain radiograph revealed expansive osteolytic growth involving the right distal radius, and a giant cell tumor of the bone. MRI was performed. Imaging assessment revealed a soft-tissue mass involving the right distal radius, which appeared to be a benign giant cell tumor; however, the possibility of malignancy could not be excluded.

A wide surgical resection of the tumor was performed. The solid mass originated from the distal radius. On gross examination, the encapsulated tumor measured $6 \times 5 \times 3.5 \mathrm{~cm}$. The tumor was excised with the involved radiocarpal joint and ulnar periosteum, proximally up to $\sim 8 \mathrm{~cm}$ from the wrist joint. Reconstruction of the bony defect was performed using an autologous vascularized fibular graft. Fibular head and 

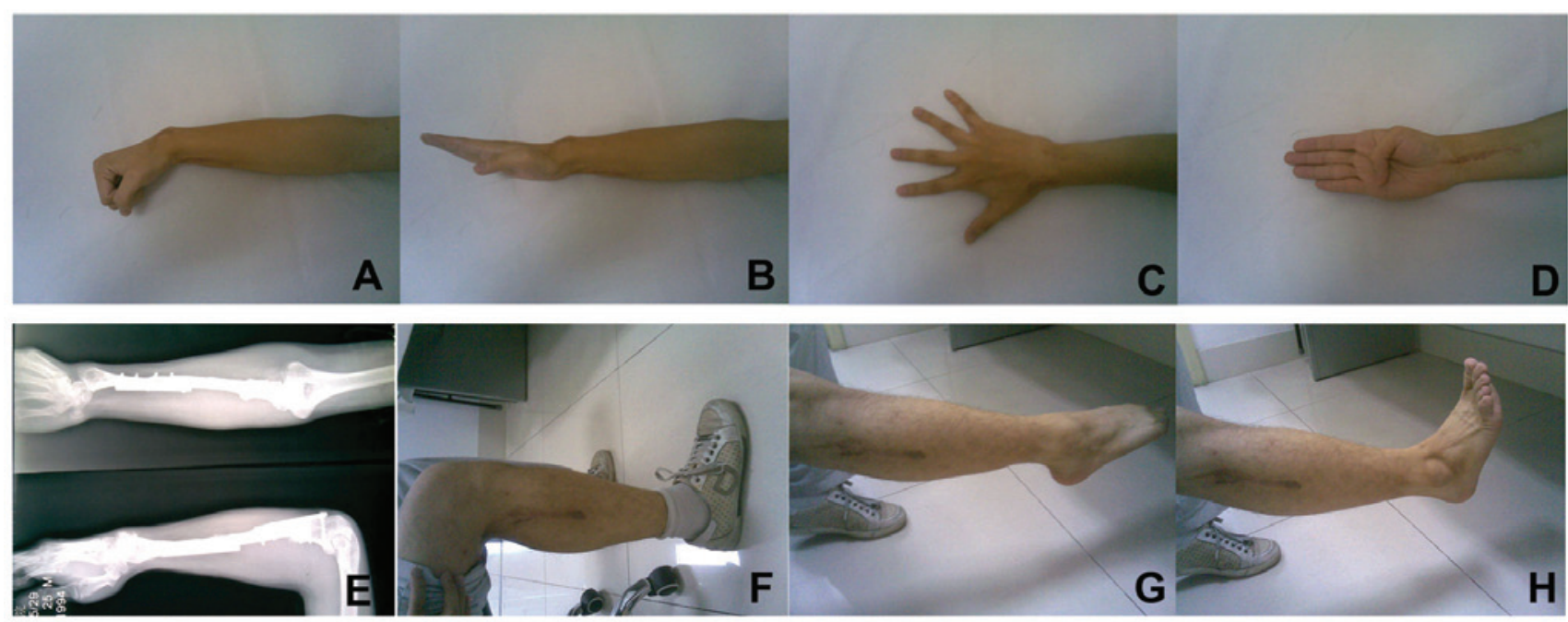

Figure 1. Functioning of the wrist, elbow, hand, knee and ankle joints after 10 years of follow-up. (A) The wrist flexion was good, (B) wrist extension was fair, (C) finger function was good and (D) the thumb opposition was good. (E) An X-ray showed that the forearm structure was stable. (F) Knee function, and (G) ankle flexion and $(\mathrm{H})$ extension function were good.

diaphysis measuring $8 \mathrm{~cm}$ were harvested from the ipsilateral leg. The head of the fibula was fitted to match the remaining radiocarpal joint in order to recreate the wrist joint. Distally, the fibular diaphysis was fixed with a radius shaft by a dynamic compression plate in order to reconstruct the forearm and wrist joint. Vessel anastomosis was performed during this procedure, with the dorsal branch of the radial artery anastomosing to the knee arteries and the accompanying vein to the head vein. A biopsy was performed following tumor resection, which resulted in a diagnosis of desmoplastic fibroma. Histologically, the hematoxylin and eosin stained specimen resembled low-grade fibrosarcoma, with banal fibroblasts infiltrating the adjacent tissue in fascicles, without mitosis.

During the 3 years immediately after the tumor resection, the patient experienced recurrence three times, involving the distal ulnar, proximal radius and soft tissue of the dorsal region of the distal forearm, respectively. An additional resection was performed following each recurrence, as well as functional reconstruction following the second and third recurrences. The proximal ulnar and distal radius were fixed by a dynamic compression plate to maintain the length of the forearm, and thumb extension restoration was conducted in order to compensate for the involved extensor hallucis muscle.

Subsequent to 10 years of follow-up, the patient achieved $45-5^{\circ}$ flexion-extension of the wrist, and $90-70^{\circ}$ pronation-supination and $100-0^{\circ}$ flexion-extension of the elbow. The function of the fingers, and the knee and ankle joints was unlimited (Fig. 1).

The patient returned to work, and at that time, MRI revealed no signs of tumor recurrence. In this case, the prognosis was very good and the patient was advised to return every 2 years for further follow-up. However, the patient chose not to return.

\section{Discussion}

Desmoplastic fibroma of the bone has been generally defined as a benign tumor that exhibits malignant behavior (8-11). The etiology of desmoplastic fibroma remains to be elucidated.
A wide range of factors, including genetic predisposition, estrogen stimulation and traumatic activation, such as fractures and surgery, have been implicated in the development of aggressive fibromatosis $(12,13)$. In the present case, the patient had a history of wrist sprains and had undergone several surgeries, therefore, an association between wrist trauma and tumor growth was suspected, in addition to an association between surgical resections and recurrence.

Due to this locally aggressive behavior, the majority of studies recommend a wide local surgical excision via the normal soft tissue (14-21). The recurrence rate has been reported to be $17 \%$ following resection, and may be as high as $55 \%$ following curettage (22). In the present case, the patient experienced three further recurrences and underwent four resections.

Wide surgical resection and a high grade of recurrence may result in significant dysfunction of the affected area. Various options have been reported in the relevant literature concerning the functional reconstruction of bone defects in the forearm, including creation of a single forearm bone from the radius and ulna, and centralizing the carpus over the single bone, a free fibular graft, a fibular head graft for the distal radius and a microvascular fibular graft, and allografts (4-7). The technique utilized in the present study to create the articular surface of the radiocarpal joint involved a microvascular fibular head graft. In a total of three surgical procedures, a single bone forearm was created from the radius and ulna, and the carpus was centralized over the single bone. Although a normal forearm could not be achieved, this reconstruction was an acceptable option considering the morbidity of tumor resection for forearm functioning.

The long-term outcome for patients exhibiting extremity desmoid tumors remains to be elucidated, particularly for patients who experience repeated recurrences. In the present case, the patient experienced recurrence three times in the three years immediately after the initial surgical resection, and after 10 years of follow-up, the patient demonstrated positive hand, elbow, knee and ankle function, as well as moderate 
wrist function. The patient was satisfied with the recovery of function and was able to return to work and daily life with no limitations.

In conclusion, the present study indicates that desmoplastic fibroma is a rare tumor that exhibits locally aggressive behavior. The diagnosis is dependent on the correlation of clinico-radio-pathological data. The treatment of choice is a wide local excision and function reconstruction for the upper limbs.

\section{Acknowledgements}

The present study was sponsored by the Scientific Research project supported by Huashan Hospital, Fudan University (Shanghai, China; grant no. No.2013QD05)

\section{References}

1. Spear, MA, Jennings LC, Mankin HJ, Spiro IJ, Springfield DS Gebhardt MC, Rosenberg AE, Efird JT and Suit HD: Individualizing management of aggressive fibromatoses. Int J Radiat Oncol Biol Phys 40: 637-645, 1998.

2. Zlotecki, RA, Scarborough MT, Morris CG, Berrey BH, Lind DS, Enneking WF and Marcus RB Jr: External beam radiotherapy for primary and adjuvant management of aggressive fibromatosis. Int J Radiat Oncol Biol Phys 54: 177-181, 2002.

3. Ballo, MT, Zagars GK, Pollack A, Pisters PW and Pollack RA: Desmoid tumor: Prognostic factors and outcome after surgery, radiation therapy, or combined surgery and radiation therapy. J Clin Oncol 17: 158-167, 1999.

4. Gebhardt MC, Campbell CJ, Schiller AL and Mankin HJ: Desmoplastic fibroma of bone. A report of eight cases and review of the literature. J Bone Joint Surg Am 67: 732-747, 1985.

5. Kesani AK, Tuy B, Beebe K, Patterson F and Benevenia J: Single-bone forearm reconstruction for malignant and aggressive tumors. Clin Orthop Relat Res 464: 210-216, 2007.

6. Muramatsu K, Ihara K, Azuma E, Orui R, Goto Y, Shigetomi M and Doi K: Free vascularized fibula grafting for reconstruction of the wrist following wide tumor excision. Microsurgery 25: 101-106, 2005.

7. Rastogi S, Varshney MK, Trikha V, Khan SA and Mittal R: Desmoplastic fibroma: A report of three cases at unusual locations. Joint Bone Spine 75: 222-225, 2008.
8. Hattoma N, Largab A, Kafih M, Rafai M, Maher N and Trafeh M: Desmoid tumors of the shoulder-girdle (report of three cases). Chir Main 23: 184-189, 2004 (In French).

9. Berthe JV, Loréa P, De Prez C and De Mey A: A case report of desmoid tumor of the finger. Chir Main 22: 312-314, 2003 (In French)

10. Reitamo JJ: The desmoid tumor. IV. Choice of treatment, results, and complications. Arch Surg 118: 1318-1322, 1983.

11. Enzinger FM and Shiraki M: Musculo-aponeurotic fibromatosis of the shoulder girdle (extra-abdominal desmoid). Analysis of thirty cases followed up for ten or more years. Cancer 20: 1131-1140, 1967.

12. Gallucci GL, Boretto JG and De Carli P: Desmoid tumor of the forearm. Reconstructive surgery and functional result. Chir Main 28: 326-329, 2009.

13. Tsai LH, Thamboo TP and Lim AY: Desmoid tumour following a distal radius fracture - a complication or a coincidence? J Hand Surg Eur Vol 32: 330-332, 2007.

14. Wood TJ, Quinn KM, Farrokhyar F, Deheshi B, Corbett T and Ghert MA: Local control of extra-abdominal desmoid tumors: Systematic review and meta-analysis. Rare Tumors 5: e2, 2013.

15. Rock MG, Pritchard DJ, Reiman HM, Soule EH and Brewster RC: Extra-abdominal desmoid tumors. J Bone Joint Surg Am 66: 1369-1374, 1984

16. Ridders J, Ernst A, Todt I and Seidl RO: Extra-abdominal desmoid tumors. Case report and literature review. HNO 53: 639-644, 2005 (In German).

17. Pritchard DJ, Nascimento AG and Petersen IA: Local control of extra-abdominal desmoid tumors. J Bone Joint Surg Am 78: 848-854, 1996.

18. Mankin HJ, Hornicek FJ and Springfield DS: Extra-abdominal desmoid tumors: A report of 234 cases. J Surg Oncol 102: 380-384, 2010.

19. Chatelard PA, Gilly FN, Carret JP, Vauzelle JL, Brunat M, Braillon $\mathrm{G}$ and Dejour H: Extra-abdominal desmoid tumors. Therapeutic indications. Apropos of 28 cases. Acta Orthop Belg 57: 227-233, 1991 (In French).

20. Barrios RH, Leyes M, Losada JI, Schweitzer D and Amillo S: Extra-abdominal desmoid tumors. Diagnostic-therapeutic considerations and review of the literature. Rev Med Univ Navarra 39: 14-20, 1995 (In Spanish).

21. Ayadi K, Trigui M, Zribi M and Keskes H: Extra-abdominal desmoid tumors: 7-year outcome after surgical treatment in 12 patients. Rev Chir Orthop Reparatrice Appar Mot 89: 385-392, 2003 (In French).

22. Böhm P, Kröber S, Greschniok A, Laniado M and Kaiserling E: Desmoplastic fibroma of the bone. A report of two patients, review of the literature, and therapeutic implications. Cancer 78: 1011-1023, 1996. 